\title{
Can Minimum Wages Cause a Big Push? Evidence from Indonesia
}

\author{
Jeremy R. Magruder*
}

March 16, 2011

\begin{abstract}
PRELIMINARY AND INCOMPLETE: PLEASE DO NOT CITE

Big Push models suggest that local product demand can create multiple labor market equilibria: one featuring high wages, formalization, and high demand and one with low wages, informality, and low demand. I demonstrate that minimum wages may coordinate development at the high wage equilibrium. Using data from 1990s Indonesia, where minimum wages increased in a varied way, I develop a difference in spatial differences estimator which weakens the common trend assumption of difference in differences. Estimation reveals strong trends in support of a big push: formal employment increases and informal employment decreases in response to the minimum wage. Local product demand also increases, and this formalization occurs only in the non-tradable, industrializable industries suggested by the model (while employment in tradable and non-industrializable industry also conform to model predictions).
\end{abstract}

\section{Introduction}

Wage floors traditionally play a simple role in partial equilibrium models of firm behavior: higher wages imply higher marginal costs, lower labor demand, and lower profits. This simple but powerful intuition has guided a great deal of economic analysis and intuition regarding the likely effects of externally imposing higher wages, for example

\footnotetext{
*University of California, Berkeley. e-mail jmagruder@berkeley.edu. I think Paul Gertler, Ann Harrison, Marieke Kleemans, Alex Rothenberg, and John Strauss for help with various aspects of the data and Michael Anderson, Alain de Janvry, Ted Miguel, and Elisabeth Sadoulet for several useful discussions. All mistakes are naturally my own.
} 
through legal minima. However, if local consumption is an important component of product demand, then the story quickly becomes much more nuanced. In that event, higher wages still remain a cost borne by firms; however, they may also increase the size of the local market which, in turn, can increase either quantities sold or prices and positively influence profitability and labor demand.

This insight is at the core of classical big push modelling. For example, RosensteinRodan (1943) suggests that "if... one million unemployed workers were taken from the land and put... into a whole series of industries which produce the bulk of the goods on which the workers would spend their wages.... it would create its own additional market, thus realizing an expansion of world output." Rosenstein-Rodan clarifies: because of this potential of market formation, wages paid by local firms have the externality of boosting local product demand. The same intuition is formalized in more recent big-push modelling, such as Murphy, Schleifer, and Vishny (1989; henceforth MSV). MSV demonstrate that, if workers require a wage premium to supply labor to the formal sector, than multiple equilibria are possible with industrializing and non-industrializing equilibria coexisting for some parameter values. In other words, if firm profits are tied to local consumption, then firms create an externality by paying high wages: the size of the market for other firms increases with worker wages and wealth.

In popular culture, this insight is usually attributed to Henry Ford, who famously doubled wages at his auto plants to five dollars a day in January 1914. Ford wrote "our own sales depend on the wages we pay. If we can distribute high wages, then that money is going to be spent and it will serve to make... workers in other lines more prosperous and their prosperity is going to be reflected in our sales" (Ford 1922 p. 124-127). The idea that a firm could unilaterally use wages to increase demand for its own product enough to offset wage cost seems unlikely and is dismissed by Rosenstein-Rodan (1943), and Ford's own statements on the matter were inconsistent (Taylor 2003). As a result, economists have traditionally interpreted Ford's wage innovations as an efficiency wage 
(e.g. Raff and Summers 1989) . However, while it may be not be in a firm's private interest to pay higher wages, a key intuition of coordinated development is that a firm's profits may depend on the wages paid by local firms more generally. This insight was dubbed the "high wage doctrine" and endorsed by policy makers and economists during the great depression, who saw stimulating consumer demand through wages as an important policy vector to combat the economic downturn (Taylor 2003 extensively documents the policy discussion). That is, this high wage doctrine reemphasizes this wage externality. While profits may be decreasing in a firm's own wages, they may in fact be increasing in the wages of other nearby firms, which can happen so long as prices do not fully adjust ${ }^{1}$. In the MSV modelling, this is achieved through a bisected market of industrialized high productivity monopolists with prices bounded by a low-productivity informal fringe, though one can also describe insufficient price adjustment if some goods are tradable and hence have prices which are unaffected by innovations in local wages 2 .

In this paper, I add a minimum wage to the MSV big push model, and show that it can change a multiple-equilibrium setting to one where only the industrialized equilibrium remains as long as some firms are constrained by the minimum wage. To my knowledge, this is the first paper to explore the consequences of minimum wages in a big push framework ${ }^{3}$ I then argue that 1990s Indonesia presents an appropriate case study, as real minimum wages rose rapidly in a varied way and then dropped quickly with the inflation rate in the South East Asian financial crash. These changes combine with flexible government policy to create substantial spatial and intertemporal variation in the wage rate. I develop a difference in spatial differences estimator based on the spatial fixed effects in Conley and Udry (2010) and Goldstein and Udry (2009) which weakens the standard

\footnotetext{
${ }^{1} \mathrm{~A}$ critique of the high wage doctrine involving the quantity theory of money is presented in Taylor and Selgin (1999). This critique is not relevant to the subnational analysis below.

${ }^{2}$ Though not pursued here, if consumers have CES utility over tradables and non-tradables, and firms are competitive with cobb-douglass production, then one can show that so long as tradable and nontradable goods are sufficiently complementary, the price of tradable goods rises enough in the presence of minimum wages to motivate increased employment.

${ }^{3}$ A search of the keywords "minimum wage" and "big push" on econlit turns up zero hits as of 3/1/2011.
} 
difference-in-difference identification assumption of similar trends to allow trends to be non-parametric over time but spatially local. This estimation procedure reveals several surprising trends which are congruent with a Big Push in Indonesia. First, formal sector work increases with the minimum wage, while informal sector work decreases, which is predicted by the MSV model but is the opposite of the prediction a partial equilibrium analysis would achieve. I also document that local real demand increases, particularly for non-food items, suggesting that minimum wages are boosting demand, the causal channel highlighted in the model. The big push model also has strongly heterogeneous predictions across industries, depending on tradability and industrialization potential. I look at tradable and non-tradable, formal and informal manufacturing firms to document that while the expansion of the formal sector and retraction of the informal sector are powerful enough trends to be statistically significant for the labor force on average, they are observed in non-tradable manufacturing but not tradable manufacturing, consistent with model predictions. In contrast, in services (where industrialization potential is minimal) there is an expansion of informal work, while retail consolidates in response to rising minimum wages. Finally, I document that trends seem unlikely to be created through reverse causality or migration and I close by suggesting some explanations for why these policies may have been successful in 1990s Indonesia, but were widely considered failures in depression-era America.

\section{Model}

The model is a straightforward adaptation of Murphy, Schleifer, and Vishny (1989). There are $Q$ goods, each produced by a distinct industry. A representative consumer has CobbDouglass Utility over these goods, $U(x)=\sum_{x=1}^{Q} \ln (x)$. In MSV's original case, each good could be produced by two production technologies: an informal fringe, which produces and remunerates at unity, and an industrializing, increasing returns to scale tech- 
nology which requires an input of $F$ units of labor to access but then can produce $\alpha>1$ units with each additional unit of labor. Because the informal fringe will compete away any prices above unity, prices are fixed at that level.

Finally, MSV suppose that industries feed local demand. With Cobb-Douglass utility, the consumer will spend $y / Q$ on each good; at unit prices this is the production amount which requires either $\frac{y}{Q}$ units of fringe labor or $\frac{y}{\alpha Q}+F$ units of industrialized labor. Therefore, if the monopolist pays wage $w$, she earns $\pi$ profits

$$
\pi=\frac{y}{Q}\left(\frac{\alpha-w}{\alpha}\right)-F w
$$

For our purposes, suppose that $y$ is wage income (very similar results are achieved if $y$ is the sum of wage income and profits). Then, if all firms industrialize,

$$
y=\frac{w y}{\alpha}+Q F w+L-\frac{y}{\alpha}-Q F
$$

or, solving for $y$,

$$
y=\frac{L+Q F(w-1)}{\left(1-\left(\frac{w-1}{\alpha}\right)\right)}
$$

Thus, industrialization is profitable for the last firm, if

$$
\frac{L+Q F(w-1)}{Q\left(1-\left(\frac{w-1}{\alpha}\right)\right)}\left(\frac{\alpha-w}{\alpha}\right)-F w>0
$$

or

$$
\frac{L}{Q}\left(\frac{\alpha-w}{\alpha}\right)>F
$$

If no one industrializes, $y=L$; thus industrialization is unprofitable for the first firm if

$$
\frac{L}{Q}\left(\frac{\alpha-w}{w \alpha}\right)<F
$$


Which suggests that for certain values of $F$, there can be multiple equilibria whenever $w>1$.

\subsection{Minimum wages and the Big Push}

MSV motivate the potential for multiple equilibria from the possibility that workers will require a wage premium to sell labor to industrializing firms, perhaps because of worse working conditions or perhaps because of needs related to urbanization. A key point is that in this model, minimum wages can encourage development. There are two obvious channels for this to take place:

First, if the equilibrium with no minimum wage is selected, the presence of a minimum wage may allow coordination at the superior industrializing equilibria. The idea behind this is simple, and motivated by MSV's observation that expectations of development become self-fulfilling in a model like this. Both equilibrium in this model are ex ante equally sensible. The minimum wage may make formal the expectation that other firms will pay higher wages, which would push firms towards the industrialized equilibrium. While I don't formally develop this equilibrium selection rule here, one might think it would particularly credible in a time of internationally financed economic growth like 1990s Indonesia.

Second, if the minimum wage can be enforced on some workers in the undeveloped equilibrium (perhaps because some industries are owned by monopolists but able to operate at low wages, for example, if the wage premium that workers need is heterogeneous), then a minimum wage can rule out the undeveloped equilibrium in some parameter spaces. Specifically, suppose $\delta L$ earn the minimum wage, $\bar{w}, \bar{w} \geq w$. As a result, when the next firm (after the first $\delta$ ) is considering paying a higher wage, it observes wage income

$$
\delta \bar{w} L+(1-\delta) L
$$


and is willing to invest if

$$
\frac{\delta \bar{w} L+(1-\delta) L}{Q}\left(\frac{\alpha-\bar{w}}{\alpha \bar{w}}\right)>F
$$

It is easily verified that there are levels of $F$ such that there would be undeveloped equilibria without a minimum wage but that there is none with the minimum wage if

$$
\delta \bar{w}+(1-\delta)>\left(\frac{\alpha-w}{\alpha-\bar{w}}\right)\left(\frac{\bar{w}}{w}\right)
$$

So that if the minimum wage successfully binds on at least some workers, then it is possible for the economy to only allow industrializing equilibria. This is certainly true locally at $\bar{w} \cong w$, and it is easy to verify that a similar result holds for $\bar{w}<w$.

\subsection{Industry Heterogeneity}

The MSV model, above, assumes that industries are homogeneous. They have two attributes which are important to demand-driven development. First, they are untradable and their product is consumed locally (that is, they are "articulated" in the language of de Janvry and Sadoulet (1983). Second, they all have the potential for industrialization. Homogeneity in these assumptions makes the model transparent and tractable; however, to develop a broader number of empirical restrictions it is necessary to loosen them. Suppose, therefore, that the MSV modelling assumptions of untradability and potential for industrialization are relevant for fraction $\eta$ of industries. Fraction $\gamma$ are tradable (and all industrializable). For these firms, demand is not related to local income, thus, they receive some return $R$ from using $\tilde{\gamma} L$ units of labor which they demand inelastically so long as they are profitable. $1-\gamma-\eta$ are neither industrializable nor tradable (for example, services). These industries can only be produced through the informal fringe, and thus their labor demand is always equal to $y / Q$. 
In this scenario, non-tradable, industrializable firms behave very similarly: we now have two equilibria if

$$
\frac{L(1+\tilde{\gamma}(w-1))}{Q w}\left(\frac{\alpha-w}{\alpha}\right)<F<\frac{L(1+\tilde{\gamma}(w-1))}{Q(w-\eta(w-1))}\left(\frac{\alpha-w}{\alpha}\right)
$$

where the non-industrializable equilibrium can again be ruled out by minimum wages if there is some compliance. Tradable firms, whose product demand is not subject to local demand, behave differently: minimum wages evoke either a zero or a negative employment response. Since the industrialized equilibrium is associated with a higher $y$ than the non-industrialized firms, this model would suggest that untradable industries which cannot industrialize increase their labor demand.

\subsection{Empirical Predictions}

The modelling above highlights the potential of a labor standard to produce demanddriven development. It also highlights that a broad number of conditions are necessary for this potential to be realized, including the presence of unutilized technological potential, the articulation of local firms with consumer demand, and that minimum wages be appropriately set (one can easily verify that very high minimum wages can serve to eliminate the industrializing equilibrium, as well). In the empirical analysis, I will take several predictions to the data. First, if minimum wages are inducing big-push-style development motivated by local demand, we should observe that formal sector employment in untradable industries with the potential for industrialization increases while informal sector employment in these industries decrease in response to an increased minimum wage. Examining untradable industries with no potential for industrialization, such as services, we should observe informal sector employment to increase when minimum wages increase. Third, examining tradable industries, we should observe no increase, and potentially a decrease, in formal sector employment in response to minimum wages. Finally, 
an additional prediction of this modelling is that minimum wages are associated with growth in local product demand: indeed, this is precisely the mechanism which drives this model, and one that I will test below.

\section{Minimum Wages in Indonesia}

The first half of the 1990s was a time of rapid economic expansion in Indonesia. Alongside this economic expansion, minimum wages grew very quickly in 1990s Indonesia in a varied way. Commentators suggest that there were two primary pressures which caused this rise in minimum wages: pressure from the US government, associated with concurrent anti-sweatshop activism; and a desire to enforce a national minimum wage which could purchase a better-than-substistence consumption bundle (see Rama 2001 for a more extensive discussion). The schedule and timing of these minimum wage increases was determined by regional tripartite local councils, including representatives of the ministry of manpower as well as local employers and employees; this procedure led to a varied growth in minimum wages with 32 different minimum wage regimes countrywide. The regimes are either provinces or collections of districts within a province. Real minimum wages (averaged across the country) are presented in figure 1; this graph makes clear that minimum wages doubled in real terms between 1990 and 1997 before falling as prices rose alongside the financial crisis. Other studies of these minimum wages (Alatas and Cameron 2008; Harrison and Scorce 2010; Rama 2001) have used difference-in-differences or control function approaches and found that these minimum wages reduced employment, though sometimes only for a subset of firms, and all using data prior to the crisis. Most similar to this study, Alatas and Cameron (2008) completed a matched differencein-differences on firms inside or outside of Jakarta, and found that small firms reduced employment in response to minimum wages but that there was no effect on large firms.

If these minimum wages fundamentally changed labor markets in Indonesia, it seems 
necessary that they affected the wage distribution. Given the high level of informality, we may be concerned about whether minimum wages were in fact enforceable in 1990s Indonesia. In particular, before turning to employment effects of minimum wages, it is useful to construct wage histograms to verify both that the minimum wage did distort the wage distribution, and that this minimum wage was sufficiently high to evoke credible demand responses. Figure 2 presents the log wage histogram for across years and Indonesia, where wages are normalized so that 0 indicates a log wage equal to the log minimum wage in that wage group. Clearly, enforcement is far from perfect, as about a third of full-time wage workers earn below the minimum in their district. However, there is also a clear jump in wage densities at the minimum wage, indicating that for some jobs at least, the minimum wage does affect wages. Analysis below will focus on differences between nearby districts. Figure $3 \mathrm{a}$ and $3 \mathrm{~b}$ presents minimum wage histograms for individuals who live within 25 miles of a minimum wage boundary. In Figure 3a, wages are normalized relative to the minimum in the higher wage regime. In Figure $3 b$, they are normalized relative to the minimum in the lower wage regime. As the reader can see, there is a clear jump in density at the minimum in the own-regime in all cases which is not present in the alternate wage regime. In other words, people who live nearby each other but under different minimum wage laws have wages distorted according to their own laws, so that laws are enforced discontinuously at the border.

\section{Empirical Strategy}

Employment effects of labor regulation are a traditional topic in economics, and are surveyed in Blau and Kahn (1999); Nickell and Layard (1999); and Freeman (2009) in developing countries. The majority of these estimates are constructed through either differencein-difference style estimators (e.g. Besley and Burgess 2004, Bertrand and Kramarz 2002; Neumark and Wascher 1992), comparisons across small regions of space (e.g. Dube, 
Lester, and Reich 2010), or some combination of these two approaches (e.g. Card and Krueger 1994; Magruder 2010). Dube, Lester, and Reich (2010) summarize the distinctions between these two approaches, which in minimum wage studies in the US have tended to find small or positive employment effects of minimum wages under close spatial comparisons and negative employment effects using the difference-in-differences strategy.

Identification by spatial discontinuity and difference in differences posit two alternate forms for endogeneity. In either case, the concern is that minimum wage laws are different in different districts because of some underlying characteristics of the labor market. In the case of Indonesia, we may be most concerned that the tripartite councils succeeded in their explicit goals of maintaining similar real wages and that the differences in nominal minimum wages focus on underlying differences in the price paths of different districts. Given that local inflation rates seem likely to be related to economic activity, this could lead to bias in estimation which presumes common trends across treatment and control areas. A spatial regression discontinuity approach would take advantage of economic theory suggesting that the capability to trade should render prices and other economic conditions similar across nearby districts. In this case, nearby labor markets would make good comparison groups if policy makers target minimum wage policy in response to aggregate labor market characteristics rather than specific characteristics of labor markets at the borders. The assumption on targeting at the aggregate (policy group) level rather than the level of individual districts seems appealing and will be tested in the robustness section $4^{4}$ That said, a spatial discontinuity strategy is vulnerable to any differences

\footnotetext{
${ }^{4}$ Moreover, since the hypothesized difference is one of local product markets and consumption demand, such an approach also requires that consumption demand is more localized than the confounding market characteristics which minimum wages may be targeted on. Of course, product markets will vary in their localization depending on their tradability, and below empirical restrictions based on this fact are developed. Nonetheless, there is good reason to expect that product markets are sufficiently local, at least for some goods. The literature has documented that the markets for consumer goods and restaurant are tremendously local (with large market shares within five miles) even in the US, where infrastructure is strong and access to transport is good (e.g. Anderson and Matsa 2010 for restaurants, Holmes 2009 and Jia 2005 for consumer goods).
} 
between nearby districts, including differences in legislative environments. Differencein-difference identification relies on the familiar assumption that trends would remain the same in the absence of changes in minimum wage law. This assumption seems likely to hold in Indonesia if the changing time paths of minimum wage are due more to external pressure or the somewhat arbitrary exercise of bureaucratic power, but is less tenable if these time paths of policy are indeed the result of careful planning and targeting.

This paper will estimate the effects of minimum wages on employment in three ways. First, I consider a standard difference-in-difference specification,

$$
y_{i t}=\alpha_{i}+\delta_{t}+\beta\left(\text { minwage }_{i t}\right)+\gamma X_{i t}+\varepsilon_{i t}
$$

where $y_{i t}$ is employment in district $i$ in year $t$, minwage $i t$ is the real minimum wage, and $X_{i t}$ is a vector of controls. As discussed above, this approach will yield consistent estimates of the effects of minimum wages on employment if changes in the minimum wage are unrelated to changes in local labor market conditions. Following, I use spatial-temporal fixed effects to estimate a spatial discontinuity, following Conley and Udry (2010), Goldstein and Udry (2009), and Magruder (2010). This procedure allows minimum wages to be related endogenously to observations, but requires that the endogeneity is similar among spatially proximate districts. More specifically, it specifies that the "true" underlying structural equation is

$$
y_{i t}=\delta_{t}+\text { Bminwage }_{i t}+\gamma X_{i t}+v_{i t}+\varepsilon_{i t}
$$

where $v_{i t}$ is unobserved but related to minwage $e_{i t}$ and $\varepsilon_{i t}$ is exogenous. The idea behind this specification is that labor market characteristics at time $t$ are related to the level of the minimum wage. However, because of the potential for local trade, those characteristics are similar at time $t$ for other districts within some radius $R$, so that if we call this set of districts $R(i)$, then $E\left[v_{i^{\prime} t} \mid i^{\prime} \in R(i), X_{i t}\right.$, minwage $]=E\left[v_{i t} \mid X_{i t}\right.$, minwage $]$. Since every 
district-year will have a unique radius and unique labor market effect, it is not possible to represent these effects as a matrix of dummy variables as is conventionally done in fixed effects analysis. However, we can still treat the spatial effects as nuisance parameters and estimate the within estimator,

$$
\begin{aligned}
y_{i t}-\sum_{i^{\prime} \in R(i)} \frac{y_{i^{\prime} t}}{n_{R(i)}}= & \beta\left(\text { minwage }_{i t}-\sum_{i^{\prime} \in R(i)} \frac{\text { minwage }_{i^{\prime} t}}{n_{R(i)}}\right)+\gamma\left(X_{i t}-\sum_{i^{\prime} \in R(i)} \frac{X_{i^{\prime} t}}{n_{R(i)}}\right) \\
& v_{i t}-\sum_{i^{\prime} \in R(i)} \frac{v_{i^{\prime} t}}{n_{R(i)}}+\varepsilon_{i t}-\sum_{i^{\prime} \in R(i)} \frac{\varepsilon_{i^{\prime} t}}{n_{R(i)}}
\end{aligned}
$$

where $n_{R(i)}$ is the number of district-year observations within radius $R$ of district $i$. Since $E\left[v_{i^{\prime} t} \mid i^{\prime} \in R(i), X_{i t}\right.$, minwage $]=E\left[v_{i t} \mid X_{i t}\right.$, minwage $]$, the endogenous component of the error term disappears in expectation and so if we make an assumption of strict exogeneity similar to those used elsewhere in fixed effects analyses $\left(E\left[\varepsilon_{i^{\prime} t} \mid\right.\right.$ minwage $\left._{i^{\prime \prime} t}, X_{i^{\prime \prime} t}\right]=$ $\left.0 \forall i^{\prime}, i^{\prime \prime} \in R(i)\right)$, then equation 12 will consistently estimate the effects of minimum wage law.

Of course, there may be some circumstances in which spatial discontinuity may not hold. For example, provincial boundaries may be correlated with other legal differences which affect local labor markets in a discontinuous way, or infrastructure may imperfectly link two (physically proximate) differences. For this reason, I also estimate a difference in spatial differences (hence DSD), which loosens the assumptions of both difference-indifferences and spatial discontinuity estimation. Specifically, I estimate

$$
\begin{aligned}
y_{i t}-\sum_{i^{\prime} \in R(i)} y_{i^{\prime} t}= & \left(\alpha_{i}-\sum_{i^{\prime} \in R(i)} \alpha_{\iota^{\prime}}\right)+\beta\left(\text { minwage }_{i t}-\sum_{i^{\prime} \in R(i)} \frac{\text { minwage }_{i^{\prime} t}}{n_{R(i)}}\right) \\
& +\gamma\left(X_{i t}-\sum_{i^{\prime} \in R(i)} \frac{X_{i^{\prime} t}}{n_{R(i)}}\right)+v_{i t}-\sum_{i^{\prime} \in R(i)} \frac{v_{i^{\prime} t}}{n_{R(i)}}+\varepsilon_{i t}-\sum_{i^{\prime} \in R(i)} \frac{\varepsilon_{i^{\prime} t}}{n_{R(i)}}
\end{aligned}
$$

This approach will be consistent under either the assumptions of difference-in-difference estimation or the assumptions in spatial discontinuity estimation, and can be understood 
as a generalization of either. From the perspective of spatial discontinuity, this approach asks how labor market characteristics are discontinuously different between nearby districts in year $t$ as a function of sharp differences in the minimum wage in that year, but controls nonparametrically for differences between nearby districts which persist over the length of the panel. From the perspective of difference-in-differences, this approach loosens the assumption on symmetric trends: rather than requiring districts to have labor market trends which are unrelated to the presence of minimum wage law (except through causal mechanisms), this approach allows observations to have non-parametric trends, so long as those trends are shared among nearby districts (as theory would suggest). Since this estimation strategy will be consistent whenever either a spatial discontinuity or a difference in differences produces consistent estimates, these will be my preferred results.

\subsection{Standard Errors}

The discussion of estimation strategies emphasizes two dimensions of correlation within observations. First, observations of districts seem likely to be characterized by a serially correlated component of the error term, which suggests the need for clustering at the observation level (e.g. Bertrand, Duflo, and Mullainathan 2002). In practice, convention normally clusters at the level of policy groups. Secondly, the theoretical discussion suggests that labor markets are similar across small regions of space, suggesting the desirability of spatial clustering (Conley 1999). Moreover, the spatial demeaning will generate such a correlation even in the absence of an underlying one. Thus, it is important to cluster over space as well. In practice, I allow observations which are physically close (with 0.5 degrees latitude and longitude) or in the same policy group in any year to be related. This is a special case of the Conley (1999) errors, where observations are defined as economically close if they are either physically close or in the same policy group, and also can be understood as the more computationally intensive procedure outlined in Cameron, Gelbach, and Miller (2009). Small cluster numbers may be an issue as well, 
particularly in one of the data sets; I return to this possibility in the Data section.

\section{Data}

Two data sets are used in this exercise, and summary statistics of the main variables from each are provided in Table 1. The first data set is waves 1, 2, and 3 of the Indonesia Family Life Survey (IFLS), a panel data set which began in 1993 with 7,224 households and grew to include all a large number of split-off households so that 10,435 households were interviewed in 2000. Sample selection was completed so that baseline households are representative of 83 \% of Indonesia's population. Waves 1, 2, and 3 take place in 1993, 1997, and 2000. The IFLS is further notable for it's low attrition rate, with $95 \%$ of original households recontacted in 2000, and over $90 \%$ surveyed in all three years. Individual level data allowed the construction of wage histograms used above, and population-level data will be useful in allowing measurement of informal economic activity as well as controlling for demographic changes. Moreover, it will allow control for endogenous migration effects; thus, we will be able to answer whether individual outcomes change as a result of changes in minimum wage policy. The second dataset, Statistics Industry, is an annual census of all manufacturing firms in Indonesia with at least 20 employees collected by the Indonesian government statistical agency. Data are aggregated to the district (Kabupaten) level; coverage includes 209 districts annually for 10 years (1990-2000, with 1997 omitted due to data unavailability). The manufacturing census has two primary strengths: first, it fully characterizes formal employment in manufactures over the ten years of coverage. Thus, we can directly examine formal sector employment using that data. Second, it allows a great deal of firm-specific data, allowing us to disentangle, for example, employment in exporting firms from those which serve domestic markets. Employment numbers of firms in a particular category from these data are therefore the sum of employment across firms in that category in that district in that year, with zeros imputed for districts where 
zero firms register with the census. Given that manufacturing firms with greater than 20 workers are legally obligated to register with the census, this imputation seems reasonable; results which use only the (endogenously changing) sample of districts with positive employment numbers are available from the author. Interestingly, spatial discontinuity approaches remain broadly similar using this approach, but difference-in-difference approaches reveal different estimates, as one would expect if the intertemporal attrition of districts is representing economically meaningful information. The IFLS sampling procedure excludes some minimum wage groups, so rather than 32 groups of coverage, 21 are represented in these data. Thirty-two is probably sufficient for cluster asymptotics to represent reasonable approximations; however, twenty one is small enough that we may be somewhat concerned. There is an active debate on the robustness of a variety of measures to prevent overrejection of the null hypothesis in the event of small numbers of clusters, with Cameron, Gelbach, and Miller (2009) finding simulation evidence that a wild cluster bootstrap-t test performs best. However, these methods are not extraordinarily familiar, and haven't been adapted for multiple non-nested clusters which I argue above are necessary; moreover, Kline and Santos (2011) find less optimistic results for wild bootstraps in the presence of specification error. I treat this approach as a robustness test and present p-values from these tests in appendix table 1; most of the primary results are slightly noisier but still pass conventional statistical significance thresholds. Cameron, Gelbach and Miller (2009) also find that an ad-hoc approach of using critical values from a $t_{G-2}$ distribution (where $G$ is the number of clusters) works reasonably well in the range of 20 clusters 5 . The $1 \%, 5 \%$, and $10 \%$ critical values for a $t_{19}$ are about $2.87,2.1,1.73$; as the reader can verify, the main results of this paper are robust to using these more conservative critical values. Moreover, the SI, a full coverage census, is not subject to this concern, and reports similar results.

IFLS and SI geographical locations were determined from actual coordinates of IFLS

\footnotetext{
${ }^{5}$ This distribution recalls the results of Donald and Lang (2007), who derive that the $t_{G-2}$ distribution is in fact the correct distribution under a few specific assumptions.
} 
sample communities and internet resources; these are averaged to find district level coordinates. District codes which changed overtime are mapped using the IFLS documentation supplemented with Olken (2009).

\section{Results}

The theoretical modelling suggested a number of strong predictions for expected results. First, and potentially most striking, is that formal sector employment could increase in response to minimum wage increases, at least for firms which create products which are not tradable, and which have the potential for industrialization. Nearly as striking, the big push modelling suggests that these firms should see a reduction in informal employment, as the formal sector crowds out lower productivity informal work. Here, I undertake several forms of analysis to test these hypotheses. First, I examine average trends in formalization and employment; next, I verify that the causal channel of increased local expenditures does respond to minimum wages; and then I explore industry heterogeneity suggested by the model, which provides a set of strong restrictions and requires some heterogeneity in the nature of labor market evolutions if the big push model is to be believed.

Both data sets have strengths and weaknesses in terms of trying to identify how the minimum wage affects the formal and informal sectors. The IFLS, as a population survey, presents better evidence on what most people are doing in all sectors, including informal work. While the data do not include identifiers for the legal classification of work, we can divide workers into full-time wage-earners, part-time wage-earners, and the selfemployed. It seems reasonable to expect that the self-employed are primarily engaged in informal work, while a greater proportion of full-time workers should be engaged in formal sector work. Part-time wage-workers may be formally or informally employed. Thus, we can get some good evidence of the effects of the minimum wage on the informal 
sector by examining the effects of minimum wages on entrepreneurship, and some less precise estimates of the effects of minimum wages on formal employment by examining the effects of minimum wages on full-time wage work, though we will be unsure to the extent to which this wage work is truly in the formal sector. In contrast, the SI presents a complete picture of large (greater than 20 employees) manufacturing firms. This includes some firms which are not legally registered, and thus can provide some evidence on the informal sector as well. However, the large firm manufacturing sector is likely a very incomplete picture of informal employment, and so we may view this survey as best positioned to answer questions about formal employment. Moreover, some manufacturing products are highly tradable, suggesting that they may not satisfy the assumptions of untradability where we expected to see these trends.

\subsection{Employment Trends}

Table 2 presents regressions of various categories of employment on minimum wages using the IFLS and all three estimation strategies, difference-in-difference (DD), spatial difference (SD), and difference-in-spatial differences (DSD). For each estimation, I repeat the spatial estimators at 15,25 , and 50 mile bandwidths to document how estimates change as we change these (somewhat ad hoc) assumptions. The DSD estimator, which was the most robust to underlying heterogeneity, shows large positive effects of minimum wages on full time wage work whenever bandwidths are sufficiently large (and, given that this procedure does ask a great deal of the data, 25 miles may seem reasonable). The DSD estimator suggests that a $100 \%$ increase in real minimum wages is associated with approximately a $10 \%$ increase in full time waged employment. The SD estimator finds effects which are similar in sign, though often larger in magnitude as the DSD estimator, a trend which continues throughout most of the analysis in this paper.

Self Employment provides an opposite trend. The DSD estimator reveals that there is $10-20 \%$ less self employment in response to a $100 \%$ increase in the minimum wage. Once 
again, the SD estimates are similar. In contrast, the DD estimates are the opposite sign and statistically significant. Given that the difference in spatial differences loosens the difference-in-difference identification assumption, we can infer that the common trends assumption is inappropriate in this case and that a difference in difference approach could lead to mistake inference.

The divergence of results between a conventional difference-in-difference strategy and the difference-in-spatial-differences strategy warrants additional comments. First, it highlights why results in this study are different from those of previous studies of the Indonesian minimum wage. Under a common trends assumption, it appears that minimum wages are either unchanging or are shrinking formal economic activity, while informal activity is increased (in fact, if samples are restricted to the SI data in the years considered in Harrison and Scorce (2010), Rama (2001) and Alatas and Cameron (2009), then the DD estimation reveals negative significant results in formal employment, as it does in those studies, while DSD estimates are similar to those here). In contrast, when trends are allowed to differ non-parametrically subject to the restriction that they are spatially local as in the DSD estimation, there is a clear positive effect of the minimum wage on formal employment and negative effect on informal employment. Given that the DSD trends assumption is strictly weaker than the DD assumption, so that whenever the DD estimation is valid, the DSD is as well, we must prefer the DSD estimates. Second, and more importantly, this divergence speaks directly to whether reverse causality may be important. Reverse causality in this case would happen if the minimum wage was carefully targeted at regions with higher secular trends in economic growth. Obviously, both the DD and the DSD estimates would be robust to targeting on the level of economic development. Given that the same wage profile is applied to a large regions, if regional trends were affecting the regional evolution of the minimum wage, we would expect the positive relationship to show up in the DD estimates most strongly since the DD estimates reflect the average trends in the purview of the tripartite council. The fact that they show 
up only in the DSD estimates suggests that if reverse causality is important, it means that minimum wage profiles are being established for entire regions based on labor market trends in border districts and not the trends elsewhere in the region, which requires some specific and curious incentives of politicians. This is strong prima facia evidence that the effects of the minimum wage documented in this paper are not being driven by reverse causality, which will be developed further below.

Table 2 suggests that minimum wages are inducing a shift towards formalization of labor contracts, and potentially a shift towards formalization of economic activity. There are some limitations to using the IFLS to directly infer whether these new full time workers are employed in the large, formal firms modelled above. Most notably, firm size data is only available in two of the three survey years, and only coarse (two-digit) occupation data has been provided to this point (with no industry data provided). Below I'll use the fact that some of these occupations do correspond closely to one-digit industries; however it would be nice to observe whether the new full time wage jobs which are being created are the sort of job which takes place in formal firms. Here, I use the 1997 and 2000 firm size data to predict the distribution of firm sizes that employ people who work in each occupation. I then divide these into occupations which tend to work in small firm occupations (where less than 10\% are employed in firms with more than 20 workers), and large firm occupations with greater than $10 \%$ employed in these larger firms. According to this definition, $57 \%$ of workers work in small firm occupations and $43 \%$ work in large firm occupations, and these estimates are robust to alternate sensible definitions. Table 3 presents the results of estimating equation 13 where the dependent variable is working in a small firm or large firm occupation. The SD and DSD estimates are consistent in demonstrating that employment is dropping in the types of occupations which work in small firms and increasing rapidly in the types of occupations which work in large firms in response to the minimum wage distribution, consistent with a formalization response to minimum wages. 


\subsection{Market Expansion}

The analysis above suggested that employment in the formal sector is increasing in response to minimum wage growth. The model suggests that one mechanism for this shift could be local product demand. Under the big push story, firms internalize local demand, so that if nearby firms are paying higher wages, then local product markets expand which provides the impetus for industrial growth. This mechanism is testable. That is, if local demand is the sponsor for growth, we would expect local consumption to be increasing along with minimum wages, as well. Here, I use real consumption data from the IFLS. In particular, I test whether total real expenditures and expenditures on foods or nonfood products increases in response to minimum wages, where non-food products are defined as household durables and clothing, products that would be consumed even by relatively low income wage workers. As a placebo test, I also examine whether food production changes in response to minimum wages, as local food production is presumably not associated with demand for the product of local industries.

Table 4 performs this analysis. Here, and going forward, I've restricted analysis to the robust DSD approach for space reasons. One issue is that it's not immediately obvious whether the inclusion of population-level demographic covariates is desirable in estimating the effects of minimum wages on product demand. On the one hand, we care about the total size of local markets, and not the conditional correlations given demographic characteristics. On the other hand, incomplete sampling and characteristics of panel surveys means that the sample may evolve over time which may be related to consumption trends. To the extent that evolutions in consumption are due to the evolution of the panel sample, controlling for these changes would be desirable. I present both sets of estimates in Table 4. Column 1 and 2 reveal that local expenditures (and hence, local product markets) are growing in response to minimum wages. They're growing substantially: these estimates indicate that the minimum wage is being passed on more or less fully to expenditures, so a $1 \%$ increase in the minimum wage is associated with $1 \%$ increased total 
expenditures. Columns (3) and (4) present some weaker evidence that food expenditures are growing. Without controlling for covariates, we do see a large increase in food expenditures, though in most specifications this increase loses precision once we control for the population, age, gender distribution, and mean education levels in the district. Columns (5) and (6) reveal that there is a large increase in non-food consumption which is robust to the inclusion of covariates. This is reassuring, and strong evidence which speaks to the plausibility of a big-push: Most industrializable, non-tradable industries produce nonfood goods, and these estimates suggest that their market is indeed expanding Finally, Columns (7) and (8) present a placebo test, looking at food production. Food production may be reduced in response to minimum wages if workers leave agriculture, but it seems unlikely that food production would increase with industrialization and better formal sector labor market opportunities. Reassuringly, the data passes this test, and there is no statistical relationship between food production and minimum wages.

\subsection{Industry Heterogeneity}

The model suggested a number of dimensions by which different industries would respond differently to minimum wage law. The primary intuition of the big push model, that demand creates an externality which can increase formal sector employment which in turn crowds out the informal sector, is applicable only to industries which were both untradable (or at least with high costs of trade) and which have the potential for formalization. In contrast, industries which are tradable should experience zero or negative employment effects from minimum wages. For these firms, there is no externality produced by other workers increasing the market share, as their product does not specifically feed the local market. Employment effects may be small if fixed costs are substantial, but they should not be positive. The second condition, that the potential for formalization

\footnotetext{
${ }^{6}$ This trend in non-food consumption recalls the multiplier effects described in Rosenstein-Rodan (1943) and Murphy, Shleifer, and Vishny (1989).
} 
exists, was necessary for formal employment to "crowd out" informal employment. Otherwise, if the product is untradable, the externality of increased demand remains, suggesting an increase in labor demand. In industries with low potential for formalization, that growth will be consigned to the informal sector. These differences amount to strong empirical restrictions on the data. In principle, comparing across industries is similar to adding another level of differencing across industries within the data, except that theory provides stronger predictions on employment patterns than simply that one industry is a control for another. Here I consider three sectors in turn, for which the model has different empirical predictions: Manufacturing, Retail, and Services. In this section, to allow a number of analyses, I continue to focus on the difference in spatial differences estimator.

\subsubsection{Manufacturing}

Manufacturing is a sector which includes some tradable and untradable industries (or, at least, industries where the extent to which markets are local are highly variable). We also have more complete data about employment trends in manufacturing available in the SI. The model had few predictions for overall employment trends in an industry like manufacturing which is almost fully industrializable but very heterogeneous in tradability. Table 5 examines the effects on overall employment in manufacturing and on employment in registered firms and employment in unregistered firms, using the SI. Though not shown for space limitations, the SD estimator finds large differences in manufacturing employment. That is, districts with higher minimum wages than their neighbors tend to have much more manufacturing employment than their neighbors . However, these effects are not sufficiently robust to survive the DSD procedure, presented in panel 1 , suggesting that some of this difference is fixed over time (though the signs are still the

same). Overall, the evidence on an overall effect of minimum wages on manufacturing is similar to the overall trends of increased formal employment, but not very robust or usually conventionally significant. Similar results are presented in column 2, which 
examines the probability that there is zero manufacturing employment in a given district.

The SI however contains a tremendous amount of detail about industrial production and output which can help examine whether these fairly weak estimates are masking some heterogeneous impacts. Theory would suggest that heterogeneity should be quite important in an industry like manufacturing: we should see positive employment effects of minimum wages on non-tradable formal firms, negative employment effects on non-tradable informal firms, and zero or negative employment effects on tradable firms. Of course, it is difficult to precisely capture the importance of a local market in a firm's output, and as a census of large manufacturing firms, the SI is bound to undersample informal firms. Nonetheless, we can develop proxies for each of these. Here, I suggest that firms who do not export any of their product are likely to be less tradable and that firms who export at least some of their production are more likely to be tradable. Moreover, the SI does include a number of firms (about $25 \%$ ) who report having no legal status. While there is likely some misreporting here, we can at least suspect that firms that report no legal status are more likely to be informal, and that firms who report some legal status are more likely to be formal. As it turns out, nearly all firms without legal status do not export, so by these definitions we would conclude that they are not tradable, echoing the modelling assumptions.

Columns (3) through (5) of Table 5 analyzes the effects of minimum wags on regulated firms which produce for domestic production, unregulated firms which produce for domestic production, and firms which export (who are nearly all regulated; very similar estimates are obtained excluding the few unregulated firms who export). The difference in spatial differences estimator reveals a clear pattern which lines up strongly with theory: regulated, domestic firms see an increase in employment in response to the minimum wage; unregulated, domestic firms decrease employment; and there is no effect on exporting firms. Once again, the manufacturing census is revealing a clear pattern: in response to the minimum wage, formal firms are advantaged relative to informal firms, 
but only in the case where their product is consumed locally.

Table 6 conducts a similar analysis using the IFLS data. Column (1) finds weak positive overall effects, as were documented in the SI, and columns (2) and (4) demonstrate similar patterns to the SI, though they are less precisely estimated. Minimum wages are increasing the likelihood that individuals are manufacturing wage workers, which is significant provided the bandwidth is large enough. They are also less likely to be self employed in manufacturing, though point estimates are small in magnitude and not distinguishable from zero. Taken together these results are again supportive of an increase in the formal sector relative to the informal. Columns (3) and (5) of panel (B) looks at wages and profits in manufacturing. Mean wages are increasing in response to the minimum wage, as one might anticipate from an industry where much of wage work would be formal (though significance is only marginal). However, profits are not changing among the individuals who remain entrepreneurs in manufacturing 7 .

\subsubsection{Services}

Services are an industry for which industrialization potential is minimal at best. Services are also fully untradable. The model suggests therefore that there should be an increase in labor demand in services. However, that increase in demand should be felt across the board, not just in the formal sector. That is, since services cannot industrialize, we shouldn't observe the crowding out of informal employment that was demonstrated overall and in manufacturing. Table 7 examines sensitivities of several aspects of services to minimum wages using data from the IFLS. Column (1) reveals that employment in services expands when minimum wages grow, so that a $100 \%$ increase in minimum wages causes approximately $10 \%$ greater employment in services. Columns (2) and (4) reveal that this increase in employment is felt similarly in waged employment and self employment. In services, both of these are likely informal, though the IFLS does not allow us to

\footnotetext{
${ }^{7}$ It is difficult to look at wages in the SI as we only observe total wage bills rather than wages per worker. As such, such analysis is not completed here.
} 
determine carefully what fraction of wageworkers and entrepreneurs are formal versus informal. However, column (3) shows that wages aren't increasing in services. This is consistent with the idea that services are fundamentally an informal industry, with little potential for industrialization and ultimate enforcement (and hence little wage gains in response to the law). Moreover, column (5) reveals that service profits are growing with the minimum wage. Along with the growth in service entrepreneurs, this is further evidence that the overall service sector is expanding as entrepreneurs earn greater income.

\subsubsection{Retail}

It is somewhat less clear what kinds of effects we should anticipate for retail. Clearly, retail is untradable, which means we have a clear prediction that the overall sector should be growing. However, the extent to which it can be industrialized is much less clear and with that employment predictions are ambiguous. On the one hand, the retail sector is clearly different from some manufacturing industries, where one can easily envision the returns to establishing a large factory. On the other hand, there are clear gains to consolidation in the retail sector, as it is quite clear that the very micro retail establishments which are commonplace in developing countries are less profitable than the large, horizontally and vertically integrated retail sector which characterizes much retail in developed countries. Given this ambiguity, the results presents in table 8 are quite striking. Increased minimum wages are causing retail employment to contract sharply overall in Indonesia. Columns (2) and (3) demonstrate that the contraction is largest for self employment, but still evident for wage work. Of course, the IFLS data can allow only imperfect separation of formal and informal wage work, and so while it's fairly clear that informal retail is contracting (since the self employment should be virtually all informal), it is less clear what is happening to formal retail employment. At the same time, Column (5) reveals that the total profit bill of retail employment is increasing. Thus, while entrepreneurship in retail is contracting in response to the minimum wage, the total profits of entrepreneurs 
are increasing. In other words, the retail sector is consolidating in response to minimum wages, which is consistent with the formalization results in the other sectors if there are available returns to scale in retail. Consistent with formalization within retail, Column (3) documents a growth in wages per worker in response to minimum wages, as well.

\section{Robustness}

In the analysis above, I identify that local labor markets changed in Indonesia in a way consistent with the hypothesis that minimum wages were causing a big push. In particular, formal sector employment increased while informal sector employment decreased. While this trend is true on average, it is only present (in a statistical sense) in non-tradable, industrializable industries, while tradable and non-industrializable industries had different trends consistent with the modelling. I I also document that local product demand does increase in response to minimum wages, the hypothesized mechanism for this model. Here, I verify that results are robust to three potential confounders: reverse causation, prices, and migration.

\subsection{Reverse Causation}

The primary endogeneity concern in this study is that minimum wages were set according to secular trends in labor markets. Of course, the DSD estimation is robust to the possibility that more developed labor markets received higher minimum wages, but may be affected if areas are targeted for high minimum wage growth because there is knowledge that they are on a positive growth trend. The fact that a standard difference-indifference estimator does not yield the same patterns is a first piece of evidence against this hypothesis as discussed above: if the tripartite councils are setting real minimum wages to be the same, and those price differences are correlated with a variety of labor market characteristics, the trends should be strongest on the raw difference-in-differences 
which identifies average trends across minimum wage regions rather than the local spatial identification since the councils should be concerned with average outcomes within their purview. However, it remains possible that border regions are somehow different from the interior of minimum wages, possibly due to some spurious correlation or some endogeneity in the chosen minimum wage boundaries, and therefore analysis which focuses on local comparisons at the border could be affected by reverse causation without a similar affect being yielded in the raw difference in differences. If this hypothesis were true, then we would expect to see that minimum wages are closely and differentially related to employment trends in the border regions. This suggests a simple specification:

$$
\left.y_{i t}=\alpha_{i}+\delta_{t}+\beta_{1} \text { (minwage }_{i t}\right)+\beta_{2}\left(\text { minwage }_{i t} * \text { border }_{i}\right)+\gamma X_{i t}+\varepsilon_{i t}
$$

where border $_{i}$ is an indicator for being within 25 miles of a minimum wage group border. If the preceding trends of formalization and growth are being driven by reverse causation, then we should expect that $\beta_{2}$ is different from zero and has the same sign as the DSD estimates above. Table 9 performs this analysis for the key results of tables 2 through 4: the effects of minimum wages on full time wage work, self employment, firm size, and expenditures. This specification tests whether trends in minimum wages are correlated with trends in labor market characteristics differentially in border regions.

Column (1) and (2) reveal that there is no statistical difference in minimum wages based on either general trends in wage work or self employment or any differential relationship with trends in the border regions. In fact, the $\beta_{2}$ estimates are opposite in sign from the preceding estimates, suggesting that if border areas are being targeted in a differential way, it should go against estimating the striking employment results above. Column (3) has $\beta_{2}$ marginally significant: minimum wages are more positively correlated with trends in small firm employment in border areas than in interior areas; once again, this is the opposite sign of the main result and suggests that if we want to interpret this 
seriously, we should conclude that systematic wage setting is yielding conservative estimates of the effects of minimum wages on small firm growth. Columns (4), (5), and (6) show no significance in $\beta_{2}$, and all columns show no significance in $\beta_{1}$. There is therefore no evidence to suggest that minimum wages are being set in response to labor market trends, and even less evidence that they are being set differentially at borders in a way which could yield the estimates contained in this paper. Therefore, if reverse causation is important in the results presented in this paper, minimum wages are being targeted in a specific way which is tough to reconcile with sensible policy making: they must be being targeted at places which have advancing trends relative to their neighbors, but not places with advancing overall trends. This both requires a great deal of sophistication on the part of policy makers, and a confusing and hard to identify objective function.

\subsection{Prices}

As discussed in section 3 , one of the key motivations for the variation in minimum wages was to maintain a constant real wage. This suggests that a concern in analyzing these minimum wages is whether the estimation strategy does not identify systematic differences in prices. While it's not immediately clear what relationship local inflation rates should have with employment growth in particular sectors, it is clear that if there were differential inflation associated with the minimum wage, this could lead to misestimates in the local product demand specification. Since this was the prime support of the model's main mechanism, it is important to verify that the DSD technique is not picking up systematic differences in prices. The presence of trade suggests that prices should be locally similar which motivated the DSD strategy. However, both of these suggestions are theoretical rather than empirical, and some evidence would be helpful.

One limitation of the data is that we do not observe the full universe of prices and so cannot ask how prices of services or non-food items change. However, the IFLS does have data on food prices for a subset of districts, though these price data are quite variable. In 
Appendix Table 2, I normalize price data into z-scores and test whether rice, sugar, salt, and cooking oil prices are associated with real minimum wages 8 . As the reader can verify, none have a statistically significant association, and in most specifications point estimates are actually negative (though standard errors are sometimes large). This is consistent with the retail sector becoming more efficient as discussed above, and inconsistent with the idea that the DSD estimation does not adequately control for the relationship between higher minimum wages and higher inflation. Interestingly, the coefficients on a raw difference-in-differences (which does not account for spatial trends) are always positive, though they also do not achieve significance.

\subsection{Migration}

A second concern with the IFLS is that migration could skew statistics. As a panel study, the IFLS will reflect trends in the population who were initially surveyed. If individuals who are well-suited for formal sector work respond to the presence of higher minimum wages by systematically migrating to high minimum-wage districts, that could skew employment results (though the presence of jobs for them is still an interesting phenomenon). The first column of table 10 illustrates that individuals do indeed respond to changes in minimum wage rates by migrating. The dependent variable in this column is the fraction of individuals in that district-year who entered the panel in a different district. At least at the larger bandwidths, there is strong evidence that a larger fraction of surveyed individuals are migrants when wages are higher than in nearby districts. Immediately, this suggest the potential for bias in estimates due to migration. Fortunately, it is very possible to perform a robustness analysis. In particular, rather than using a person's present location and minimum wage in constructing employment statistics we can always use the samples' original districts. That is, we can ignore the information

\footnotetext{
${ }^{8}$ The IFLS also has consistent data on fish and beef prices; however, these are frequently non-reported. There are not, any significant relationships between fish and beef prices and minimum wages in the DSD estimator.
} 
on their current location and test whether individuals experience changes in type of employment or overall expenditures based on the minimum wages in the district that they began the sample in, rather than the district that they currently are in. Column (2) repeats the migration analysis, but asks this time whether people are more likely to migrate from their home district based on the home districts minimum wages. If minimum wages are producing economic opportunities as the analysis above has suggested, we would not expect an increase in out-migration due to higher minimum wages. Indeed, Column (2) finds zero effects on outmigration as a result of minimum wage growth, and taken together, these two columns represent strong evidence that individuals are migrating to places with higher minimum wages.

The remaining columns of table 10 repeat the analysis of tables 2 and 3, using the origin-province minimum wages rather than those of the the current province. As the reader can verify, no results change. That is, even though there is a systematic migration response to higher minimum wages, this response isn't the variation that drove analysis in the previous section. The origin analysis shows that if an individual resides in a district which expects a future wage profile which is better than nearby neighbors, that individual can anticipate engaging in the labor force in a more formal way.

\section{Discussion and Conclusions}

The early 1990s were a time of massive foreign investment and rapid economic growth for Indonesia. During that time period, the government quickly raised minimum wages. According to a Big Push Model, if 1990s Indonesia was characterized by the potential for higher productivity industrial structures, and if the minimum wages were designed appropriately, then they could achieve a big push - a movement from a low wage, low consumption, informal labor market to a high wage, high consumption, formal labor market. This paper has presented evidence that such a shift did indeed take place. When 
minimum wages rose in one district relative to their neighbors, that district observed an increase in formal sector employment and a decrease in informal employment. It also observed an increase in local expenditures, which is consistent with the hypothesized mechanism of the big push: that local product demand increases labor demand. Moreover, this increase was only observed in local industries which can be industrialized and do supply local demand, supporting the model further. Tradable manufacturing firms saw no growth in employment, and untradable, but non-industrializable services saw an increase in informal employment.

These trends were identified through a difference in spatial differences analysis, an approach which weakens the identification assumptions of both difference-in-differences and spatial discontinuities. This weakening of assumptions was important: a raw differencein-differences would have missed these connections. This suggests two things: first, in a context where labor law is varied, the underlying identification assumptions may be quite important. In this case, assuming average trends to be the same across districts with different minimum wage profiles would have underestimated employment effects. Second, it suggests that reverse causality is unlikely to be the explanation for these controversial findings. Minimum wage laws were established for entire regions. If governments were establishing these varied laws due to variation in the secular trends present in these regions, then they should have been responding to the average trend present in those regions, rather than local trends at the borders. Since the raw difference-in-differences suggests that average trends in employment are not strongly related to the minimum wage profiles, the potential for reverse causality to be creating these positive estimates is minimized, and I confirm also that trends at the border are not differentially associated with minimum wage trends.

This big push discussion strongly recalls much older economic thought which has been widely discredited within the profession. Few economists today argue as 1920s and 1930s economists did, that increasing wages and local demand could be a motor for eco- 
nomic growth. One reason is the limited (and potentially negative) effect these policies had on depression-era America. There are of course many differences between 1990s Indonesia and 1930s America. One, as a less-developed country receiving substantial foreign investment, Indonesia may have had new access to potential, unadopted, and profitable technologies that simply needed a market. A second is that much of the 1990s were a time of growth in Indonesia, when sticky wages may have limited wage growth (the opposite of conditions in the depression). Finally, Harrison and Scorce (2010) show that anti-sweatshop activism also raised labor standards in foreign firms without an accompanying drop in employment. This indicates that wages may have indeed been below marginal products in the 1990s, reducing coordination and creating an opening for policy. Of course, the analysis employed in this paper cannot determine whether any of these conditions were important for these results. Further research, both empirical and theoretical is needed in considering the role of labor standards throughout the business cycle in modern less developed countries.

\section{References}

AlatAs, V., And L. A. CAmeron (2008): “The Effect of Minimum Wages on Employment in a Low-Income Country: A Quasi-Natural Experiment in Indonesia," Industrial and Labor Relations Review, 61(2), 201-223.

Anderson, M. L., And D. A. MATSA (2011): “Are Restaurants Really Supersizing America?," AEJ: Applied Economics, 3(1), 152-88.

Bertrand, M., E. Duflo, And S. Mullainathan (2004): “How Much Should We Trust Difference-in-Differences Estimates?," Quarterly Journal of Economics, 119(1), 249-275.

Bertrand, M., AND F. KRAmARZ (2002): “Does Entry Regulation Hinder Job Creation? Evidence From the French Retail Industry," The Quarterly Journal of Economics, 117(4), 1369-1413.

Besley, T., And R. Burgess (2004): “Can Labor Regulation Hinder Economic Performance? Evidence from India," The Quarterly Journal of Economics, 119(1), 91-134.

BlAU, F. D., AND L. M. KAHN (1999): "Institutions and Laws in the Labor Market," in Handbook of Labor Economics, Volume 3, chap. 25, pp. 1399-1461. Elsevier-North Holland. 
Cameron, A. C., J. B. Gelbach, and D. L. Miller (2006): “Robust Inference with Multi-Way Clustering," mimeo, University of California, Davis.

Cameron, C. A., J. Gelbach, and D. Miller (2008): “Bootstrap-Based Improvements for Inference with Clustered Errors," Review of Economics and Statistics, 90(3), 414-427.

Card, D., And A. B. Krueger (1994): “Minimum Wages and Employment: A Case Study of the Fast-Food Industry in New Jersey and Pennsylvania," The American Economic Review, 84(4), 772-793.

Conley, T. G. (1999): "GMM Estimation with Cross-Sectional Dependence," Journal of Econometrics, 92(1), 1-45.

Conley, T. G., And C. R. Udry (2008): “Learning About a New Technology: Pineapple in Ghana," The American Economic Review, forthcoming.

De Janvry, A., And E. Sadoulet (1983): “Social Articulation as a Condition for Equitable Growth," Journal of Development Economics, 13(3), 275-303.

DONALD, S. G., AND K. LANG (2007): "Inference with Difference-in-Differences and Other Panel Data," The Review of Economics and Statistics, 89(2), 221-223.

Dube, A., T. W. Lester, And M. Reich (2010): "Minimum Wage Effects Across State Borders: Estimates Using Contiguous Counties," Review of Economics and Statistics, 92(4), 945-964.

FORD, H. (1922): My Life and Work. Doubleday, Page, Garden City, NY.

Freeman, R. B. (2009): “Labor Regulations, Unions, and Social Protection in Developing Countries: Market Distortions or Efficient Institutions?," NBER Working Paper No. 14789.

Goldstein, M., And C. Udry (2008): “The Profits of Power: Land Rights and Agricultural Investment in Ghana," The Journal of Political Economy, forthcoming.

HARrison, A., AND J. SCORCE (2008): "Multinationals and Anti-Sweatshop Activism," The American Economic Review, forthcoming.

Holmes, T. J. (2008): “The Diffusion of Wal-Mart and Economies of Density," NBER working paper No. 13783.

JiA, P. (2008): “What Happens When Wal-Mart Comes to Town: An Empirical Analysis of the Discount Industry," Econometrica, 76(6), 1263-1316.

KLIne, P., And A. SAntos (2011): “Higher Order Properties of the Wild Bootstrap Under Misspecification," mimeo, Univeristy of California, Berkeley.

Magruder, J. R. (2009): “High Unemployment Yet Few Small Firms: The Role of Centralized Bargaining in South Africa," mimeo, University of California, Berkeley. 
Murphy, K. M., A. Shleifer, And R. W. Vishny (1989): “Industrialization and the Big Push," The Journal of Political Economy, 97(5), 1003-1026.

Neumark, D., And W. WASCher (1992): "Employment Effects of Minimum and Subminimum Wages: Panel Data on State Minimum Wage Laws," Industrial and Labor Relations Review, 46(1), 55-81.

NickelL, S., AND R. LAYARD (1999): “Labor Market Institutions and Economic Performance," in Handbook of Labor Economics, Volume 3c, ed. by O. Ashenfelter, and D. Card, pp. 3029-3084. Elselvier-North Holland.

Olken, B. A. (2009): "Merged Indonesian Kecamatan Codes," National Bureau of Economic Research, electronic data set.

RAfF, D. M. G., AND L. H. Summers (1987): “Did Henry Ford Pay Efficiency Wages?,” Journal of Labor Economics, 5(4, Part 2), S57-S86.

RAMA, M. (2001): "The Consequences of Doubling the Minimum Wage: The Case of Indonesia," Industrial and Labor Relations Review, 54(4), 864-881.

Rosenstein-Rodan, P. N. (1943): "Problems of Industrialization of Eastern and SouthEastern Europe," The Economic Journal, 53(210/211), 202-211.

TAYLOR, J., AND G. SELGIN (1999): "By Our Bootstraps: Origins and Effects of the HighWage Doctrine and the Minimum Wage," Journal of Labor Research, 20(4), 447-462.

TAYLOR, J. E. (2003): “Did Henry Ford Mean to Pay Efficiency Wages?," Journal of Labor Research, 24(4), 683-94. 
Table 1: Summary Statistics

\begin{tabular}{|c|c|c|c|c|c|}
\hline Variable & $\begin{array}{l}\text { Obs } \\
(1)\end{array}$ & $\begin{array}{c}\text { Mean } \\
(2)\end{array}$ & $\begin{array}{c}\text { Std. Dev. } \\
\text { (3) }\end{array}$ & $\begin{array}{l}\text { Min } \\
(4)\end{array}$ & $\begin{array}{l}\text { Max } \\
(5)\end{array}$ \\
\hline \multicolumn{6}{|l|}{ IFLS } \\
\hline Mean Full Time Wage Workers & 447 & 0.173 & 0.100 & 0.008 & 0.576 \\
\hline Mean Part Time Wage Workers & 447 & 0.037 & 0.031 & 0.000 & 0.216 \\
\hline Mean Self Employed & 447 & 0.302 & 0.111 & 0.049 & 0.681 \\
\hline Log Real Minimum Wage (in 1000 Rs) & 447 & 1.196 & 0.210 & 0.702 & 1.672 \\
\hline Mean Workers in Small Firm Occupations & 447 & 0.388 & 0.183 & 0.065 & 0.926 \\
\hline Mean Workers in Large Frim Occupations & 447 & 0.270 & 0.120 & 0.011 & 0.722 \\
\hline Mean Workers in Service & 447 & 0.059 & 0.053 & 0.000 & 0.271 \\
\hline Mean Wage Workers in Service & 447 & 0.026 & 0.029 & 0.000 & 0.137 \\
\hline Mean Self Employed in Service & 447 & 0.022 & 0.025 & 0.000 & 0.123 \\
\hline Mean Workers in Retail & 447 & 0.123 & 0.068 & 0.000 & 0.362 \\
\hline Mean Wage Workers in Retail & 447 & 0.029 & 0.038 & 0.000 & 0.286 \\
\hline Mean Self Employed in Retail & 447 & 0.146 & 0.089 & 0.000 & 0.565 \\
\hline Mean Workers in Manufacturing & 447 & 0.076 & 0.059 & 0.000 & 0.333 \\
\hline Mean Wage Workers in Manufacturing & 447 & 0.043 & 0.046 & 0.000 & 0.242 \\
\hline Mean Self Employed in Manufacturing & 447 & 0.026 & 0.028 & 0.000 & 0.200 \\
\hline log Sum Total Expenditures & 447 & 4.786 & 0.821 & 2.872 & 7.250 \\
\hline Log Sum Food Purchases & 447 & 4.073 & 0.748 & 2.495 & 6.296 \\
\hline Log Sum Non-Food Purchases & 447 & 4.125 & 0.892 & 2.021 & 6.766 \\
\hline Log Sum Food Produced & 447 & 2.106 & 0.923 & 0.000 & 4.584 \\
\hline \multicolumn{6}{|l|}{ SI } \\
\hline Log Production Workers & 2090 & 6.860 & 2.947 & 0.000 & 12.300 \\
\hline Indicator for zero workers & 2090 & 0.089 & 0.285 & 0.000 & 1.000 \\
\hline Log Registered, Domestic Prod. Workers & 2090 & 6.171 & 2.942 & 0.000 & 11.961 \\
\hline Log Unregistered, Domestic Prod. Workers & 2090 & 2.609 & 2.976 & 0.000 & 9.523 \\
\hline Log Exporting Workers & 2090 & 1.282 & 1.353 & 0.000 & 5.236 \\
\hline
\end{tabular}




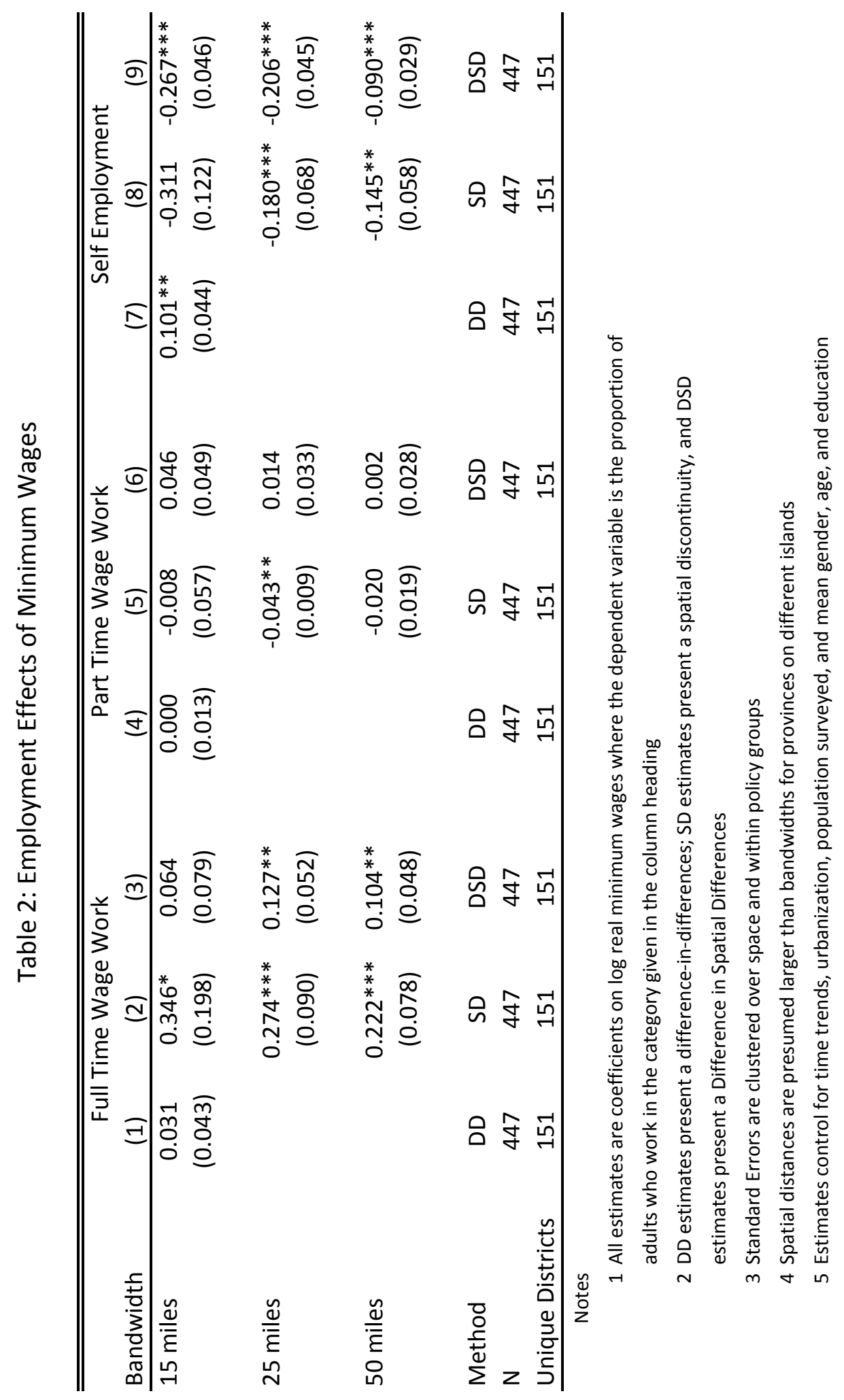


Table 3: Minimum Wage Effects on Small and Large Firm Occupations

\begin{tabular}{|c|c|c|c|c|c|c|}
\hline \multirow[b]{2}{*}{ Bandwidth } & \multicolumn{3}{|c|}{ Small Firm Occupations } & \multicolumn{3}{|c|}{ Large Firm Occupations } \\
\hline & (1) & (2) & (3) & (4) & (5) & (6) \\
\hline \multirow[t]{2}{*}{15 miles } & -0.026 & $-0.478 * * *$ & $-0.458^{* * *}$ & $0.125^{* *}$ & $0.288^{* *}$ & $0.311^{* * *}$ \\
\hline & (0.069) & $(0.161)$ & $(0.031)$ & $(0.062)$ & $(0.136)$ & $(0.060)$ \\
\hline \multirow[t]{2}{*}{25 miles } & & -0.182 & $-0.438 * * *$ & & 0.095 & $0.310 * * *$ \\
\hline & & $(0.170)$ & (0.059) & & $(0.122)$ & $(0.073)$ \\
\hline \multirow[t]{2}{*}{50 miles } & & -0.168 & $-0.360 * * *$ & & 0.123 & $0.230 * *$ \\
\hline & & $(0.137)$ & $(0.061)$ & & $(0.120)$ & (0.099) \\
\hline Method & DD & SD & DSD & DD & SD & DSD \\
\hline $\mathrm{N}$ & 447 & 447 & 447 & 447 & 447 & 447 \\
\hline Unique Districts & 151 & 151 & 151 & 151 & 151 & 151 \\
\hline \multicolumn{7}{|l|}{ Notes } \\
\hline \multicolumn{7}{|c|}{$\begin{array}{l}1 \text { All estimates are coefficients on log real minimum wages where the dependent variable } \\
\text { is the proportion of adults who work in the category in the column heading }\end{array}$} \\
\hline \multicolumn{7}{|c|}{$\begin{array}{l}2 \text { DD estimates present a difference-in-differences; SD estimates present a spatial } \\
\text { discontinuity, and DSD estimates present a difference in spatial differences }\end{array}$} \\
\hline \multicolumn{7}{|c|}{3 Standard Errors are clustered over space and within policy groups } \\
\hline \multicolumn{7}{|c|}{4 Spatial distances are presumed larger than bandwidths for provinces on different islands } \\
\hline \multicolumn{7}{|c|}{$\begin{array}{l}5 \text { Small Firm occupations have fewer than } 10 \% \text { of employees working in firms } \\
\text { with at least } 20 \text { employees, large firm occupations have more than } 10 \%\end{array}$} \\
\hline \multicolumn{7}{|c|}{6 Estimates control for time trends, urbanization, population surveyed, and mean gender } \\
\hline
\end{tabular}




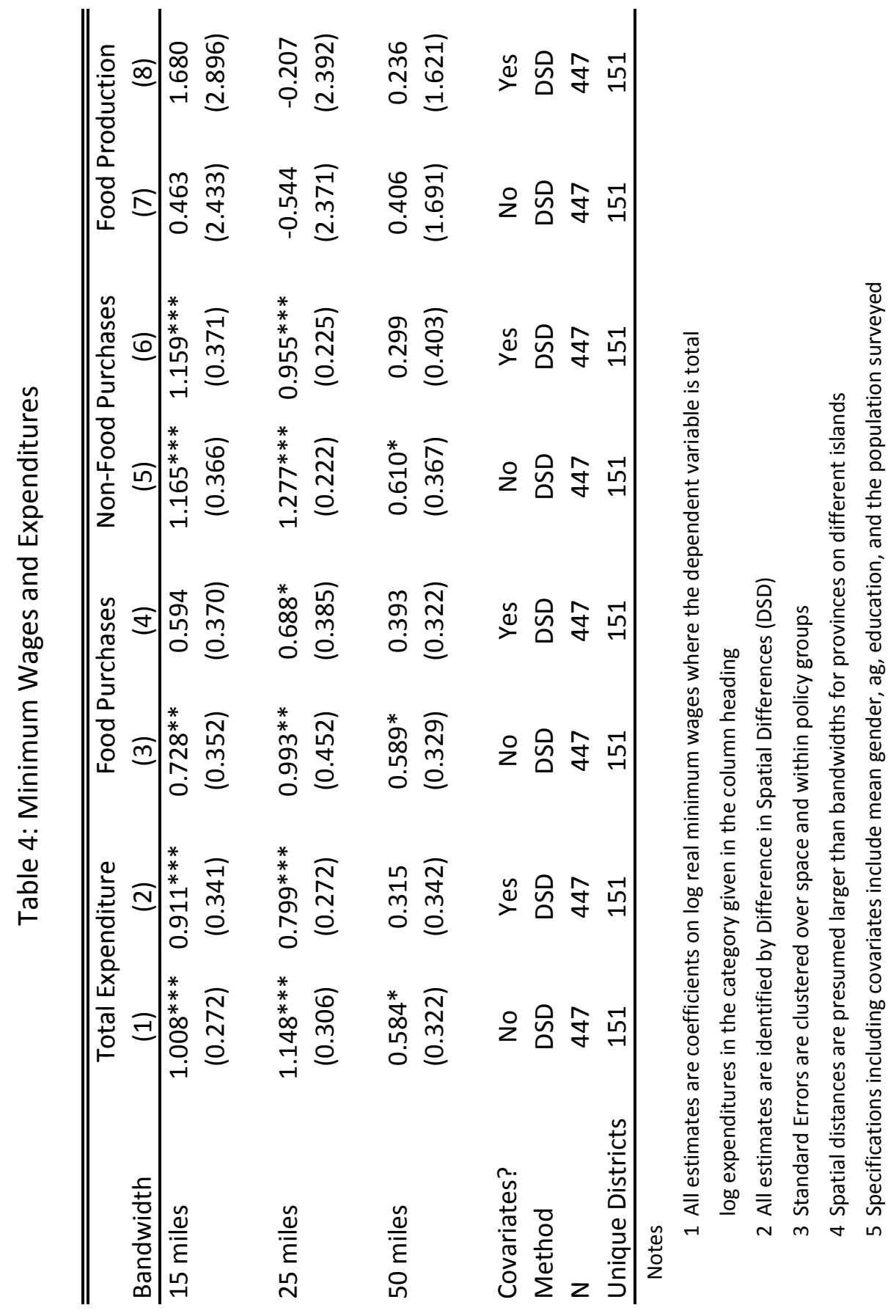


Table 5: Manufacturing Results, SI Data

\begin{tabular}{|c|c|c|c|c|c|}
\hline \multirow[b]{2}{*}{ Bandwidth } & \multirow{2}{*}{$\begin{array}{l}\text { Log Workers } \\
\text { (1) }\end{array}$} & \multirow{2}{*}{$\begin{array}{c}\text { Zero } \\
\text { Manufacturing } \\
(2) \\
\end{array}$} & \multicolumn{2}{|c|}{ Domestic } & \multirow{2}{*}{$\begin{array}{c}\text { Exporting } \\
\text { (5) }\end{array}$} \\
\hline & & & $\begin{array}{c}\text { Registered } \\
(3) \\
\end{array}$ & $\begin{array}{c}\text { Unregistered } \\
\text { (4) }\end{array}$ & \\
\hline 15 miles & $\begin{array}{c}6.425 * * \\
(2.752)\end{array}$ & $\begin{array}{c}-0.687^{* * *} \\
(0.204)\end{array}$ & $\begin{array}{c}7.201 * * * \\
(2.396)\end{array}$ & $\begin{array}{l}-3.985^{*} \\
(2.161)\end{array}$ & $\begin{array}{c}1.584 \\
(1.340)\end{array}$ \\
\hline 25 miles & $\begin{array}{c}0.420 \\
(0.940)\end{array}$ & $\begin{array}{l}-0.304 \\
(0.195)\end{array}$ & $\begin{array}{c}3.864 * * \\
(1.825)\end{array}$ & $\begin{array}{c}-2.004 * * \\
(0.905)\end{array}$ & $\begin{array}{c}0.420 \\
(0.940)\end{array}$ \\
\hline 50 miles & $\begin{array}{c}1.128 \\
(1.090)\end{array}$ & $\begin{array}{l}-0.148 \\
(0.095)\end{array}$ & $\begin{array}{l}1.631^{*} \\
(0.948)\end{array}$ & $\begin{array}{l}-0.300 \\
(0.643)\end{array}$ & $\begin{array}{c}0.334 \\
(0.412)\end{array}$ \\
\hline Method & DSD & DSD & DSD & DSD & DSD \\
\hline $\begin{array}{l}\mathrm{N} \\
\text { Unique Districts }\end{array}$ & $\begin{array}{c}2090 \\
209\end{array}$ & $\begin{array}{c}2090 \\
209\end{array}$ & $\begin{array}{c}2090 \\
209\end{array}$ & $\begin{array}{c}2090 \\
209\end{array}$ & $\begin{array}{c}2090 \\
209\end{array}$ \\
\hline Data & $\mathrm{SI}$ & $\mathrm{SI}$ & $\mathrm{SI}$ & $\mathrm{SI}$ & $\mathrm{SI}$ \\
\hline \multicolumn{6}{|l|}{ Notes } \\
\hline $\begin{array}{l}1 \text { All estima } \\
\text { variable is } \\
2 \text { All estima } \\
3 \text { Standard } \\
4 \text { Spatial dis }\end{array}$ & $\begin{array}{l}\text { are coefficients } \\
\text { ther log emplyom } \\
\text { are identified by } \\
\text { ors are clustered } \\
\text { nces are presume }\end{array}$ & $\begin{array}{l}\text { on log real minimum } \\
\text { ent in the given cate } \\
\text { Difference in Spatial } \\
\text { over space and withir } \\
\text { d larger than bandwi }\end{array}$ & $\begin{array}{l}\text { es where the de } \\
\text { or an indicator } \\
\text { erences (DSD) } \\
\text { icy groups } \\
\text { for provinces o }\end{array}$ & $\begin{array}{l}\text { endent } \\
\text { or no employment }\end{array}$ & \\
\hline
\end{tabular}


Table 6: Manufacturing Results, IFLS data

\begin{tabular}{|c|c|c|c|c|c|}
\hline \multirow[b]{2}{*}{ Bandwidth } & \multirow{2}{*}{$\begin{array}{c}\text { Total Manf. } \\
\text { Employment } \\
\text { (1) }\end{array}$} & \multicolumn{2}{|c|}{ Wage Work } & \multicolumn{2}{|c|}{ Self Employment } \\
\hline & & $\begin{array}{c}\text { Employment } \\
\text { (2) }\end{array}$ & $\begin{array}{l}\text { Wages } \\
\text { (3) }\end{array}$ & $\begin{array}{c}\text { Employment } \\
\text { (4) }\end{array}$ & $\begin{array}{l}\text { Profits } \\
\text { (5) }\end{array}$ \\
\hline \multirow[t]{2}{*}{15 miles } & 0.086 & 0.095 & -0.091 & -0.018 & 0.028 \\
\hline & $(0.057)$ & $(0.060)$ & $(0.100)$ & $(0.043)$ & $(0.153)$ \\
\hline \multirow[t]{2}{*}{25 miles } & $0.073^{*}$ & $0.085 * *$ & $0.091^{*}$ & -0.011 & -0.194 \\
\hline & $(0.040)$ & $(0.034)$ & $(0.050)$ & $(0.021)$ & $(0.142)$ \\
\hline \multirow[t]{2}{*}{50 miles } & 0.044 & $0.070 * *$ & $0.081^{*}$ & -0.018 & 0.013 \\
\hline & $(0.038)$ & $(0.033)$ & $(0.047)$ & $(0.017)$ & $(0.180)$ \\
\hline Method & DSD & DSD & DSD & DSD & DSD \\
\hline $\mathrm{N}$ & 447 & 447 & 341 & 447 & 351 \\
\hline Unique Districts & 151 & 151 & 139 & 151 & 141 \\
\hline Data & IFLS & IFLS & IFLS & IFLS & IFLS \\
\hline \multicolumn{6}{|l|}{ Notes } \\
\hline \multicolumn{6}{|c|}{$\begin{array}{l}1 \text { All estimates are coefficients on log real minimum wages where the dependent variable } \\
\text { is either the proportion workingin the given category or log payments }\end{array}$} \\
\hline \multicolumn{6}{|c|}{2 All estimates are identified by Difference in Spatial Differences (DSD) } \\
\hline \multicolumn{6}{|c|}{3 Standard Errors are clustered over space and within policy groups } \\
\hline \multicolumn{6}{|c|}{4 Spatial distances are presumed larger than bandwidths for provinces on different islands } \\
\hline 5 Estimates co & for population sury & and mean gender, & ge, and ed & & \\
\hline
\end{tabular}


Table 7: Services

\begin{tabular}{|c|c|c|c|c|c|}
\hline \multirow[b]{2}{*}{ Bandwidth } & \multirow[b]{2}{*}{$\begin{array}{c}\text { Employment } \\
\text { (1) }\end{array}$} & \multicolumn{2}{|c|}{ Wage Work } & \multicolumn{2}{|c|}{ Self Employment } \\
\hline & & $\begin{array}{c}\text { Employment } \\
\text { (2) }\end{array}$ & $\begin{array}{l}\text { Wages } \\
\text { (3) }\end{array}$ & $\begin{array}{c}\text { Employment } \\
\text { (4) }\end{array}$ & $\begin{array}{l}\text { Profits } \\
\text { (5) }\end{array}$ \\
\hline \multirow[t]{2}{*}{15 miles } & 0.028 & 0.083 & -0.140 & 0.052 & $0.806 * * *$ \\
\hline & $(0.085)$ & (0.074) & $(0.122)$ & $(0.056)$ & (0.196) \\
\hline \multirow[t]{2}{*}{25 miles } & $0.096 * * *$ & $0.0460 * * *$ & -0.080 & $0.053^{*}$ & $0.878 * * *$ \\
\hline & $(0.033)$ & $(0.018)$ & (0.096) & $(0.032)$ & $(0.214)$ \\
\hline \multirow[t]{2}{*}{50 miles } & $0.096 * *$ & $0.0348 * *$ & -0.048 & $0.038^{*}$ & 0.034 \\
\hline & $(0.041)$ & $(0.016)$ & $(0.064)$ & $(0.023)$ & $(0.146)$ \\
\hline Method & DSD & DSD & DSD & DSD & DSD \\
\hline $\mathrm{N}$ & 447 & 447 & 325 & 447 & 279 \\
\hline Unique Districts & 151 & 151 & 137 & 151 & 146 \\
\hline
\end{tabular}

Notes

1 All estimates are coefficients on log real minimum wages where the dependent variable is either the proportion workingin the given category or log payments

2 All estimates are identified by Difference in Spatial Differences (DSD)

3 Standard Errors are clustered over space and within policy groups

4 Spatial distances are presumed larger than bandwidths for provinces on different islands

5 Estimates control for population surveyed, and mean gender, age, and education 
Table 8: Retail

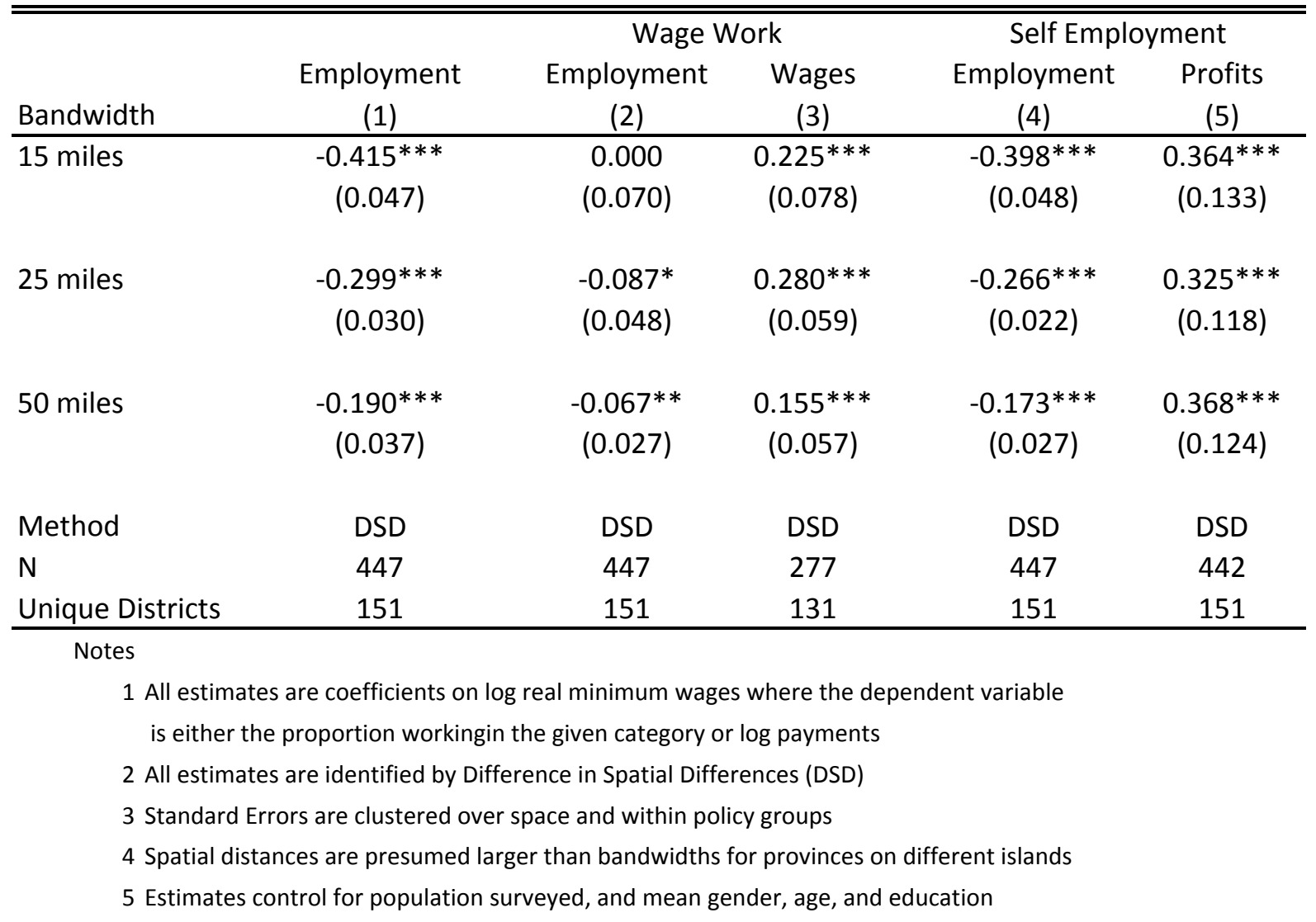




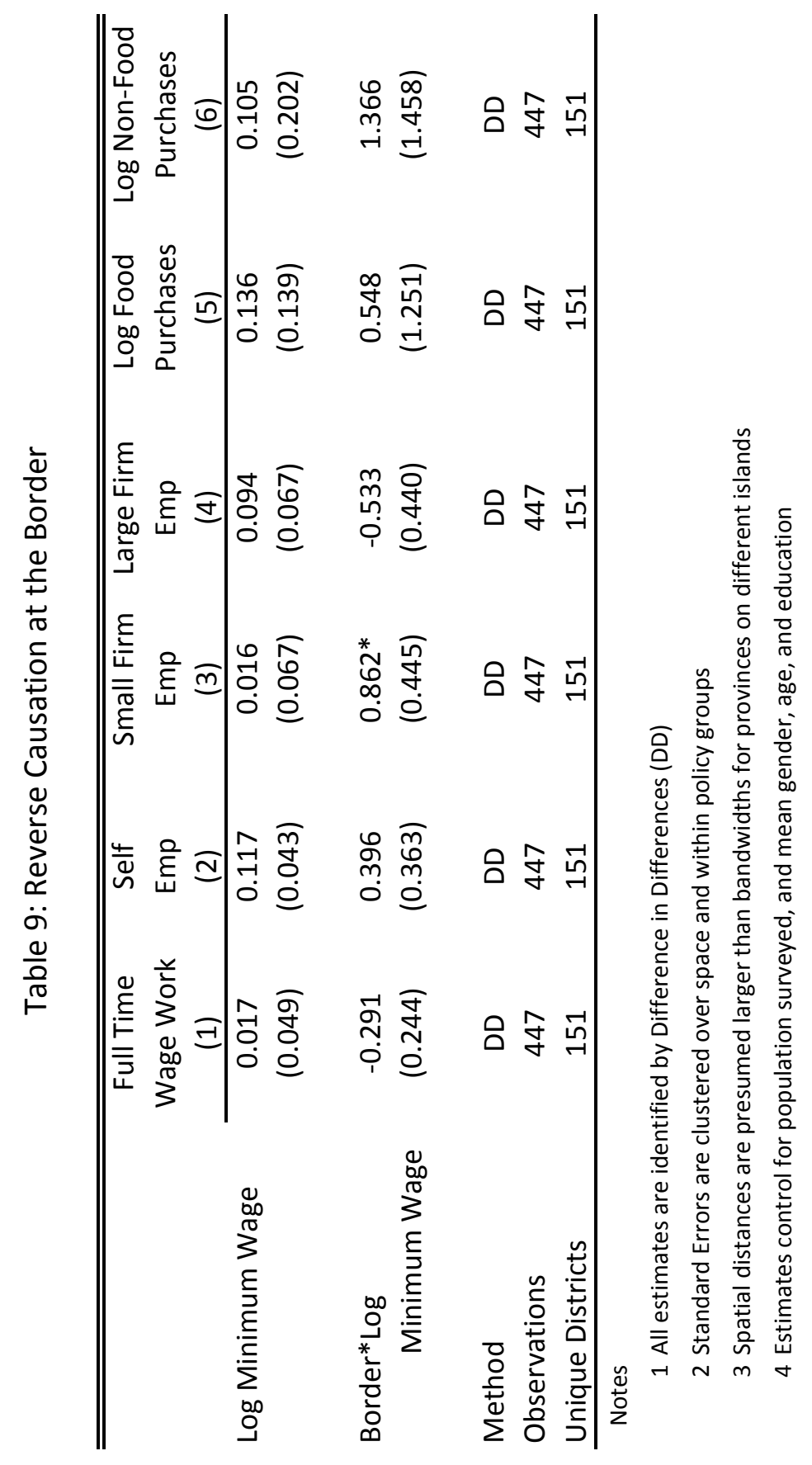




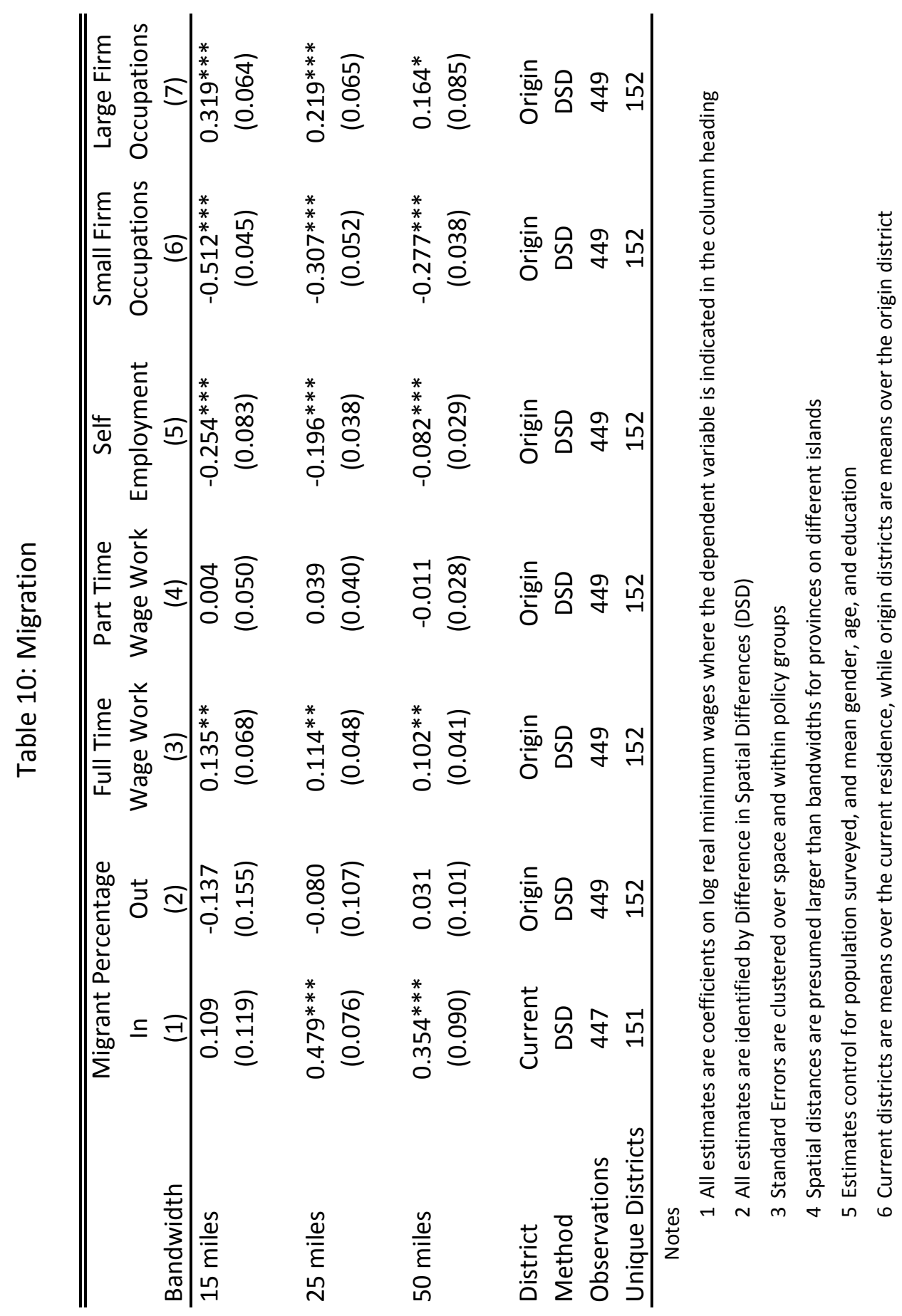


Figure 1: Minimum Wages in Indonesia

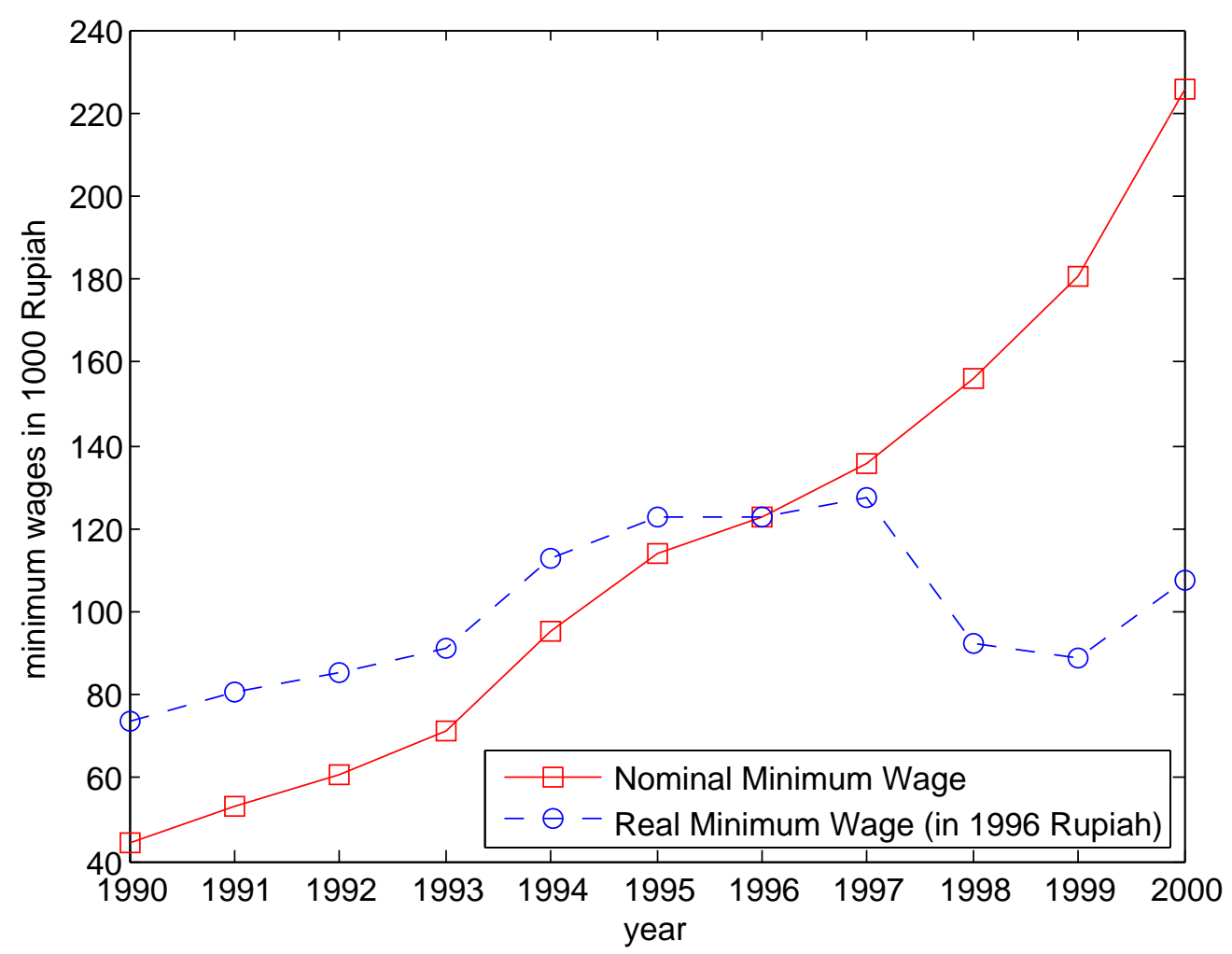

Figure 2: Density of Log Wages

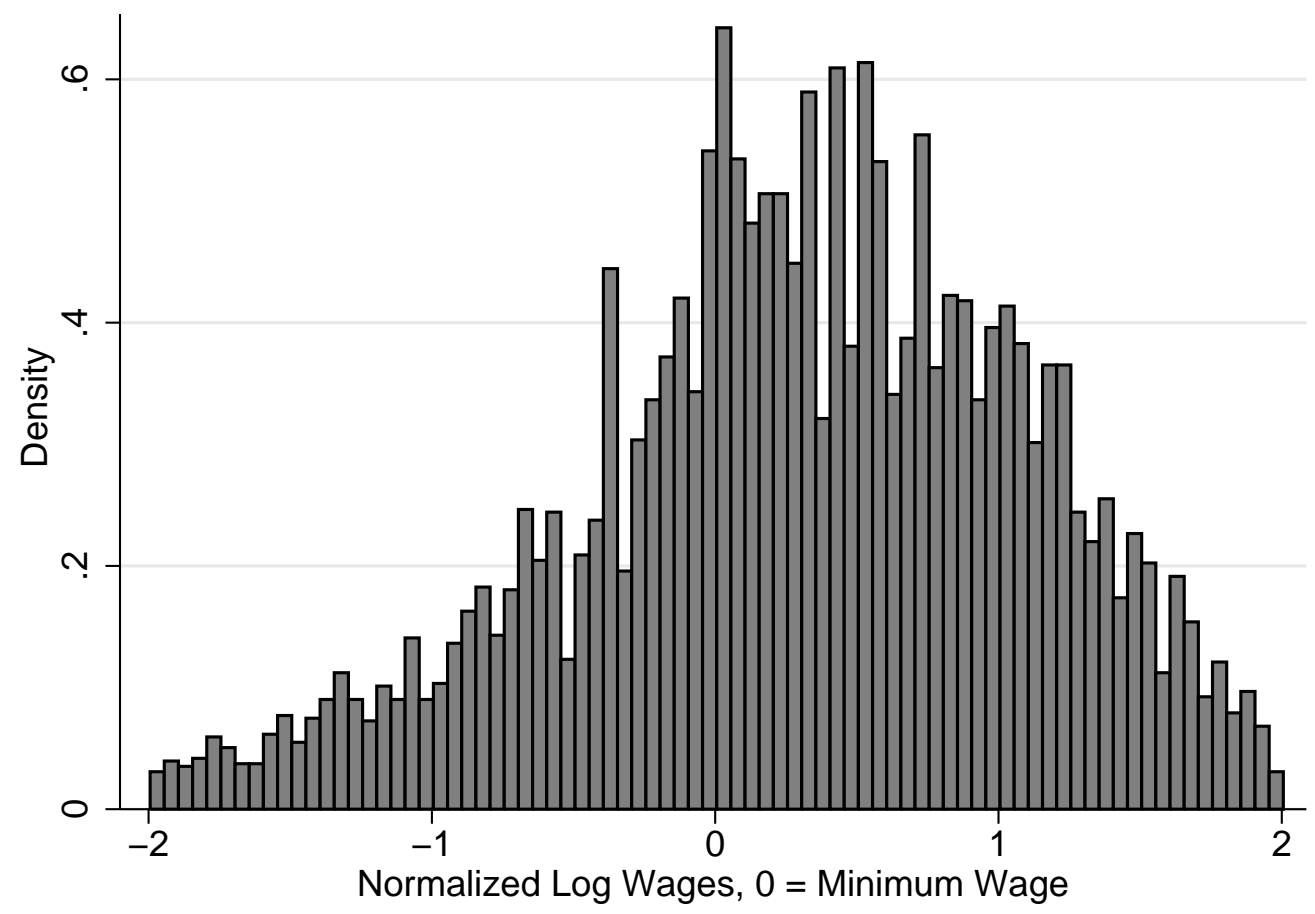




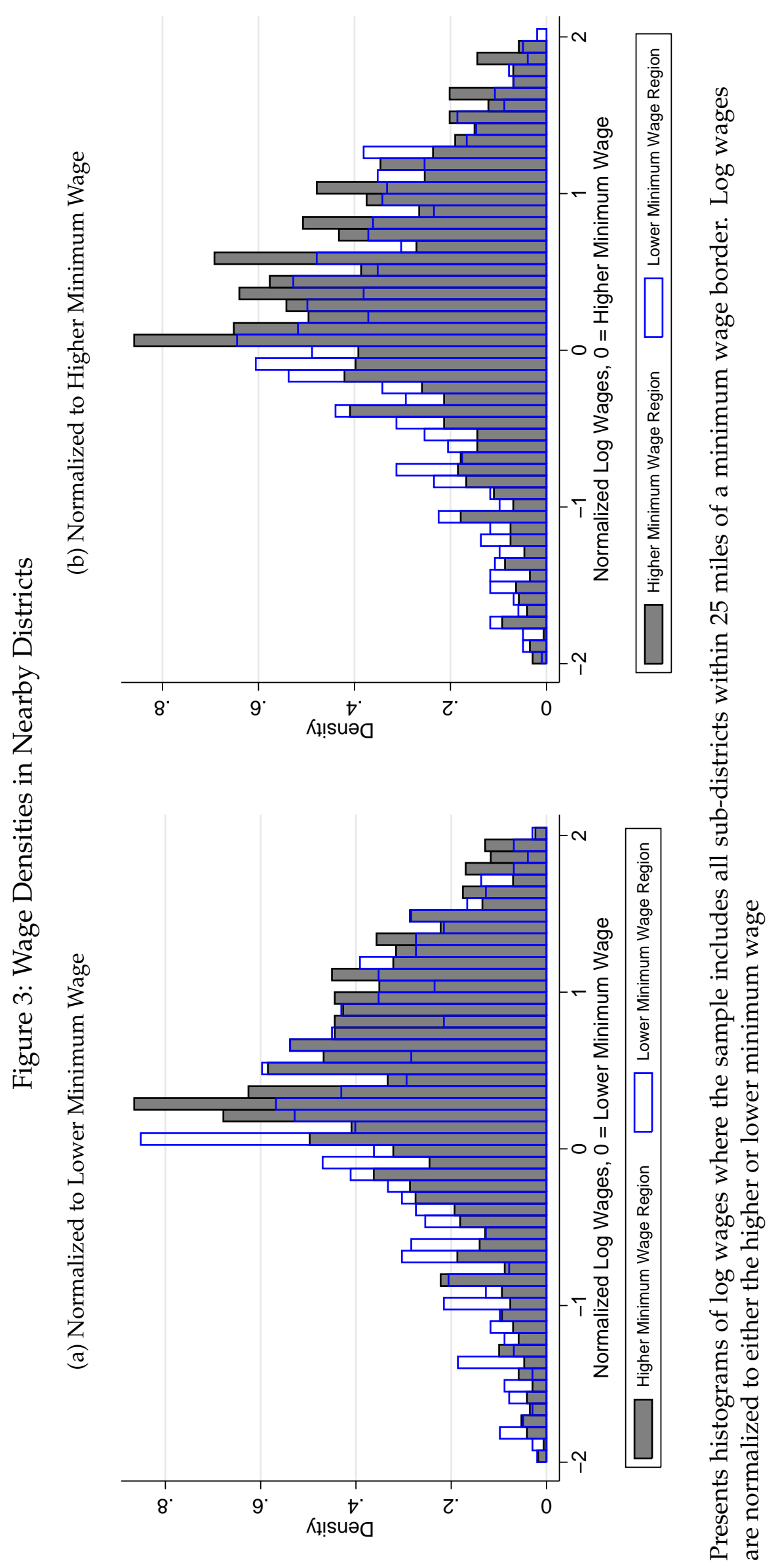

